\title{
Publisher Correction: Mechanisms of systems memory consolidation during sleep
}

Jens G. Klinzing (D), Niels Niethard (D) and Jan Born (D)

Correction to: Nature Neuroscience https://doi.org/10.1038/s41593-019-0467-3, published online 26 August 2019.

In the version of this article initially published online, the images in the second column of Fig. $4 \mathrm{a}$ were in the wrong order. The error has been corrected in the print, PDF and HTML versions of this article. 


\section{Original}

a

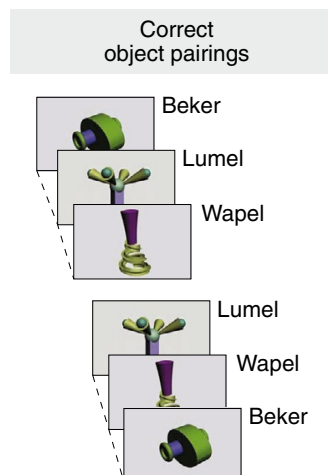

Incorrect

object pairings
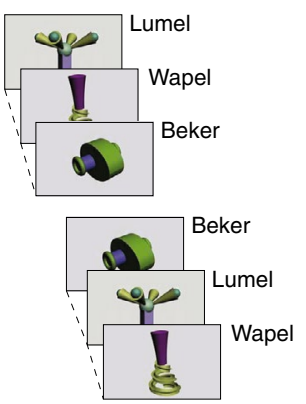

b
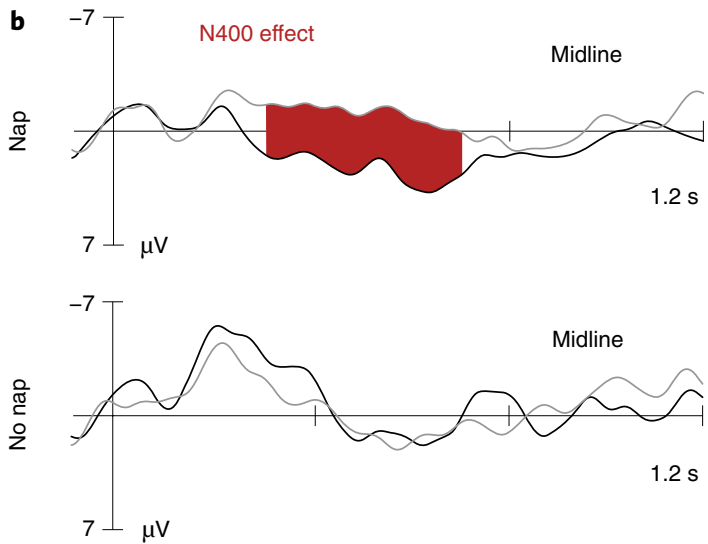

Correct novel category pairings
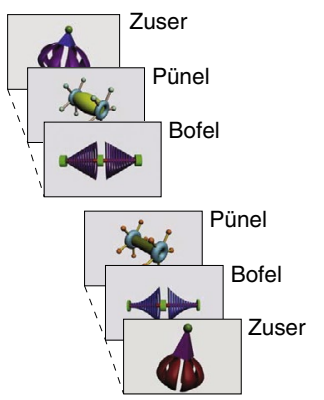

Incorrect novel category pairings

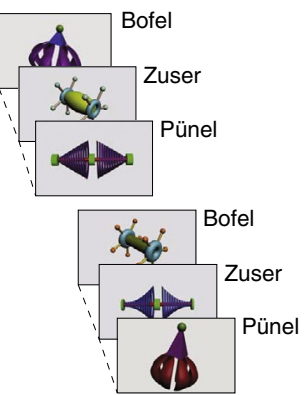

\section{Corrected}

a
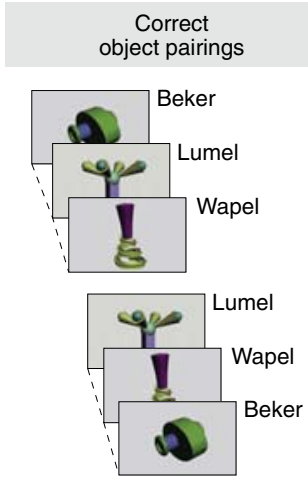

b
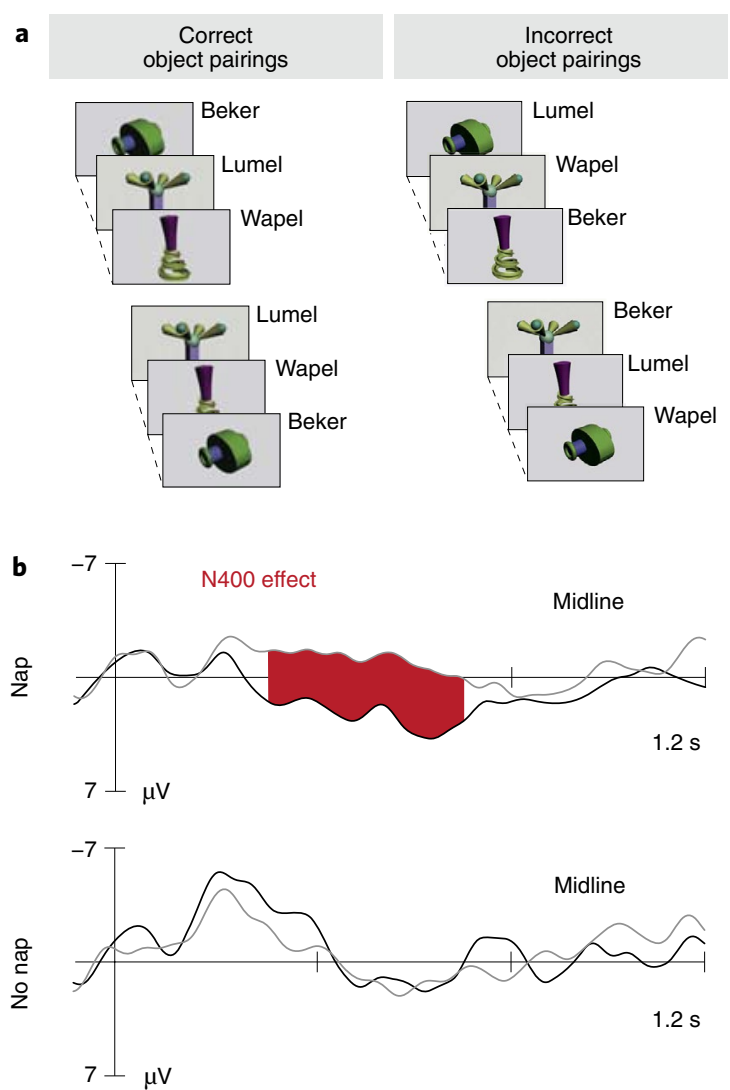

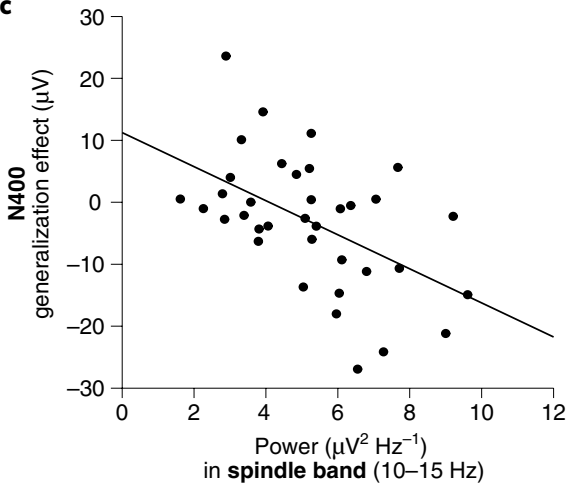

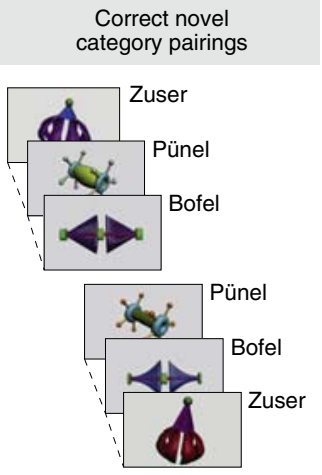

Incorrect novel category pairings
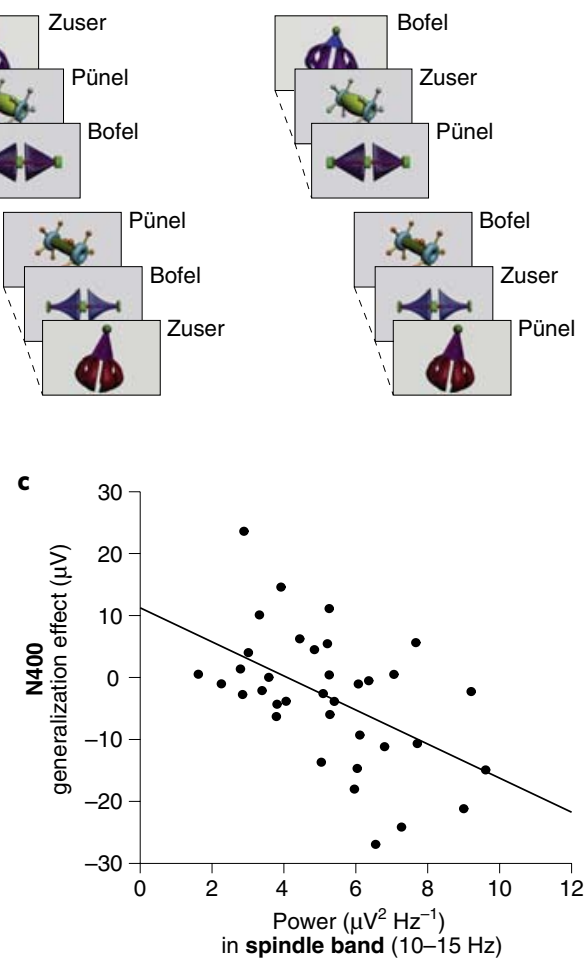

Fig. 4 | Original and Corrected. 